\title{
A RYR1 mutation associated with Malignant Hyperthermia is also associated with bleeding abnormalities
}

${ }^{1}$ Rubén J. Lopez, ${ }^{2}$ Susan Byrne, ${ }^{1,3}$ Mirko Vukcevic, ${ }^{1}$ Marijana Sekulic-Jablanovic, ${ }^{3}$ Lifen Xu, ${ }^{3}$ Marijke Brink, ${ }^{4}$ Jay Alamelu, ${ }^{5}$ Nicol Voermans, ${ }^{6}$ Marc Snoeck, ${ }^{7}$ Emma Clement, ${ }^{8}$ Francesco Muntoni, ${ }^{8}$ Haiyan Zhou, ${ }^{9}$ Aleksandar Radunovic, ${ }^{7}$ Shehla Mohammed, ${ }^{2}$ Elizabeth Wraige, ${ }^{1,10}+$ Francesco Zorzato, ${ }^{1,10^{*}}+$ Susan Treves, ${ }^{2,11,12}+$ Heinz Jungbluth

${ }^{1}$ Departments of Anesthesia and of Biomedicine, Basel University Hospital, Hebelstrasse 20, 4031 Basel, Switzerland.

${ }^{2}$ Department of Paediatric Neurology, Neuromuscular Service, Evelina Children's Hospital, St Thomas' Hospital, London SE1 7EH, UK.

${ }^{3}$ Department of Biomedicine, Basel University Hospital, Hebelstrasse 20, 4031 Basel, Switzerland.

${ }^{4}$ Department of Haematology, Evelina Children's Hospital, St Thomas' Hospital, London SE1 7EH, UK.

${ }^{5}$ Department of Neurology, Radboud University Medical Centre, 6500 HB Nijmegen, The Netherlands.

${ }^{6}$ National MH Investigation Unit, Department of Anesthesiology, Canisius Wilhelmina Hospital, 6532 Nijmegen, The Netherlands.

${ }^{7}$ Department of Clinical Genetics, Guy's Hospital, London SE1 7EH, UK.

${ }^{8}$ Dubowitz Neuromuscular Centre, Institute of Child Health, University College London, London WC1N 1EH, UK. 
${ }^{9}$ Department of Neurology, The Royal London Hospital, London E1 1BB, UK.

${ }^{10}$ Department of Life Sciences, General Pathology Section, University of Ferrara, Via Borsari 46, 44100 Ferrara, Italy.

${ }^{11}$ Randall Division of Cell and Molecular Biophysics, Muscle Signalling Section, King's College, London SE1 1UL, UK.

${ }^{12}$ Department of Basic and Clinical Neuroscience, IoPPN, King's College London, London SE5 9RX, U.K.

†These authors contributed equally.

*To whom correspondence should be addressed:

Susan Treves, Departments of Anaesthesia and Biomedicine, Basel University Hospital, Hebelstrasse 20, 4031 Basel, Switzerland.

Tel.+41-61-2652373; Fax:+41-61-2653702; E-mail: susan.treves@unibas.ch

\begin{abstract}
Malignant hyperthermia is a potentially fatal hypermetabolic disorder triggered by halogenated anesthetics and the myorelaxant succinylcholine in genetically predisposed individuals. Approximately $50 \%$ of Malignant Hyperthermia susceptible individuals carry dominant, gain of function mutations in RYR1 (which encodes ryanodine receptor type 1), though they have normal muscle function and no overt clinical symptoms. RyR1 is predominantly expressed in skeletal muscle but also to a lower extent in some immune and smooth muscle cells, suggesting that RYRI mutations may have a wider range of effects than previously suspected. Consistently, reports describing mild bleeding abnormalities in patients with malignant hyperthermia carrying gain of function $R Y R 1$ mutations have appeared. In the present report we sought to determine the
\end{abstract}


frequency and molecular basis for this symptom. We found that some patients with specific RYRI mutations had abnormally high bleeding scores, whereas their healthy relatives did not. Knock-in mice with the Malignant Hyperthermia Susceptibility RYR1 mutation Y522S (MHS RYR1Y522S) had bleeding times that were 3 times longer than their wild-type littermates. Primary vascular smooth muscle cells from RYR1 $1_{\text {Y } 522 S}$ knock-in mice exhibited a higher frequency of subplasmalemmal $\mathrm{Ca}^{2+}$ sparks leading to a more negative resting membrane potential. The bleeding defect of RYR1 $1_{\text {Y } 522 S}$ mice and of one patient was reversed by treatment with the RYR1 antagonist dantrolene, and $\mathrm{Ca}^{2+}$ sparks in primary vascular smooth muscle cells from the MHS RYR1 $1_{\text {Y522S }}$ mice were blocked by ryanodine or dantrolene. Thus, $R Y R 1$ mutations may lead to prolonged bleeding by altering vascular smooth muscle cell function. The reversibility of the bleeding phenotype emphasizes the potential therapeutic value of dantrolene in the treatment of such bleeding disorders. 


\section{Introduction}

Hemostasis is a stepwise process that causes bleeding to stop and can be grossly divided into primary and secondary hemostasis and three distinct stages. Primary hemostasis comprises (i) an instant vascular response to injury, leading to transient vasoconstriction limiting immediate blood loss, and (ii) platelet activation and aggregation, prompted by plasma Von Willebrand factor and sustained through platelet granule release that also enhances the initial vasoconstriction. Primary hemostasis results in formation of a platelet plug aimed at provisionally stopping the bleeding. Secondary hemostasis involves (iii) the sequential activation of clotting factors present in the plasma in an inactive state through a cascade of reactions, ultimately leading to the formation of a fiber-like mesh called fibrin that surrounds the provisional platelet plug and causes definite blood coagulation (1).

Bleeding disorders are clinically and genetically heterogeneous and may affect all aspects of hemostasis. The most common causes are partial deficiencies of coagulation factors and fibrinolytic proteins, deficiencies in von Willebrand factor and platelet or connective tissue disorders (1). Nevertheless mild bleeding disorders are common in the general population but their precise incidence as well as their genetic background often remain unresolved $(2,3)$.

Mutations in $R Y R 1$, the gene encoding the skeletal muscle $\mathrm{Ca}^{2+}$ channel ryanodine receptor 1 (RyR1), have a calculated frequency of 1:2000-1:3000 (4). Dominant RYR1 mutations are commonly associated with Malignant Hyperthermia $(\mathrm{MH})$, a severe pharmacogenetic reaction to halogenated anesthetics and muscle relaxants; exertional rhabdomyolysis/myalgia (ERM) (5) and the congenital myopathy Central Core Disease (CCD). Recessive $R Y R I$ mutations have been associated with the congenital myopathies Multi-minicore Disease (MmD), Centronuclear Myopathy (CNM) and Congenital Fiber Type Disproportion (CFTD) (6-8). Bleeding abnormalities have been reported in isolated patients with MH Susceptibility (MHS) (9-11) and 
homozygous mouse embryos knocked in for the Malignant Hyperthermia Susceptibility RYRI mutation Y522S (RYR1 $1_{\text {Y522S }}$ ) display massive edema and subcutaneous blood effusions at birth, suggestive of a severe bleeding disorder with antenatal onset (12).

Vascular smooth muscle cells play an important role in primary hemostasis and changes in the intracellular $\mathrm{Ca}^{2+}$ concentrations play a central mechanism regulating their relaxation and contraction (13). In addition to InsP $\mathrm{P}_{3} \mathrm{Rs}$, smooth muscle cells also express the three different RyR isoforms (13-17), and their $\mathrm{Ca}^{2+}$ homeostasis is more elaborate compared to many other excitable cell types. While InsP ${ }_{3} \mathrm{R}$ act as channels releasing $\mathrm{Ca}^{2+}$ from the endo(sarco)plasmic reticulum leading to smooth muscle cell contraction, the specific role of RyRs is more complex, and in contrast to striated muscle, RyRs are involved in smooth muscle cell relaxation $(13,18,19)$. We hypothesized that there may be a correlation between the presence of dominant, Malignant Hyperthermia-related $R Y R I$ mutations and mild bleeding abnormalities.

In the present study we investigated the potential relationship between a mild bleeding disorder and the presence of dominant, gain of function RYRI mutations; we then used the heterozygous RYR $1_{\mathrm{Y} 522 \mathrm{~S}}$ mouse model to study the mechanism linking prolonged bleeding time to $\mathrm{Ca}^{2+}$ homeostasis in isolated smooth muscle cells. Our results indicated that gain-of-function RYR1 mutations mainly affected $\mathrm{Ca}^{2+}$ homeostasis of smooth muscle cells by increasing "Spark" (spontaneous calcium release events) activity. We also demonstrated that administration of the specific RyR1 antagonist dantrolene, which is clinically approved for the treatment of Malignant Hyperthermia reactions (20-21), reversed the bleeding phenotype by decreasing spark activity in vascular smooth muscle cells. 


\section{Results}

\section{Human subjects carrying $R Y R 1$ mutations have a mild bleeding abnormality}

To investigate bleeding in $R Y R l$-associated myopathies, we invited $R Y R l$-mutated individuals and their non-mutated relatives to complete a standardized questionnaire ((Molecular and Clinical Markers for the Diagnosis and Management of Type $\underline{1}$ Von Willebrand's Disease also known as MCMDM-1VWD)) validated for the evaluation of bleeding disorders (Table 1). Patients had neuromuscular features of Malignant Hyperthermia, ERM, a congenital myopathy (Central Core Disease or Multiminicore Disease) or a combination of these features, associated mainly with dominant heterozygous $R Y R 1$ missense mutations. A proportion of patients were compound heterozygous for 2 allelic $R Y R 1$ mutations, reflecting that some $R Y R I$ mutations can be dominant with regards to Malignant Hyperthermia, but be recessives with regards to the congenital myopathy phenotype. The neuromuscular features of patients from families $1,2,4,6$, 7, 8 and of their relatives have been previously reported. (5,22-24). MCMDM-1VWD bleeding questionnaires were obtained from $24 R Y R l$-mutated patients (12 females, 12 males) and 14 relatives without the familial RYRl mutation (4 females, 10 males). Symptoms of abnormal bleeding were common in $R Y R 1$-mutated individuals, characterized by severe menorrhagia and postpartum hemorrhage in females and milder symptoms of epistaxis and easy bruising in males. One male patient reported spontaneous hematomas in association with muscle cramps, while one female patient reported an additional history of recurrent and unexplained miscarriages. Improvement of menorrhagia was reported in one female (Patient 4.2) after prescription of sodium dantrolene, the specific RyR1 antagonist used clinically to reverse acute Malignant Hyperthermia reactions $(20,21)$, for her severe ERM. Baseline hematological studies including evaluation of clotting factors and platelet aggregation studies were normal in all patients with symptoms of increased bleeding, except in patients 2.6 and 2.7 in whom abnormal von 
Willebrand factor (vWF) levels were found, and patient 5.1 who had evidence of abnormal platelet function; bleeding scores from these patients were excluded from further statistical analysis as an alternative hematological diagnosis could not be confidently ruled out. Eight out of twenty-one (38\%) patients included in the statistical analysis had a pathological bleeding score $(\geq 4)$ on the questionnaire compared to $0 / 14(0 \%)$ of controls $(\mathrm{P}=0.0118$, Fisher exact testing with 2-tailed $\mathrm{P}$ value). The mean bleeding score for patients is shown in Figure 1A.

\section{A mouse model knocked in for a human RYRI mutation associated with Malignant Hyperthermia Susceptibility shows prolonged bleeding times.}

To gain mechanistic insight linking RYRl mutations to bleeding, we used the heterozygous RYR1 Y522S Malignant Hyperthermia Susceptible mouse (12). Applying a standardized test to accurately determine bleeding times in mice (25), we demonstrate that bleeding times in RYR1 $1_{\text {Y522S }}$ mice are 2-3 longer than in their wild-type littermates (Figure 1B for bleeding times in male mice and Supplementary Figure 1 for bleeding times in female mice). Intraperitoneal dantrolene administration to wild-type mice prior to the bleeding test did not affect bleeding times. However, pre-treatment of RYR1 $1_{522 S}$ mice with dantrolene, but not with vehicle alone, reduced bleeding to the same times as those seen in their wild-type littermates (Figure 1B).

Bleeding times depend on the contraction of injured blood vessels, platelet number and function, and the activation of circulating clotting factors. We have previously not found a difference in the number and function of circulating platelets between wild-type and RYR $1_{Y 522 S}$ mice (26). RyR1 is not detectable in platelets, virtually excluding disturbed platelet function as a potential cause for the bleeding disorder. Since wild-type and RYR $1_{Y 522 S}$ knock-in littermates only differ in their $R Y R 1$, we hypothesized that these differences in bleeding times could be due 
to changes in the contraction and relaxation properties of the smooth muscle cells lining the blood vessels. Vessel reactivity can be assessed using a vessel injury model however because of their small size (with a diameter of $0.26 \pm 0.03 \mathrm{~mm}$ ) we could not accurately measure changes in the diameter of the tail artery, which would be a direct indication of contraction/relaxation. Furthermore, because of their predisposition to malignant hyperthermia deep anaesthesia was not possible in the $R Y R 1_{Y 522 S}$ knock-in mice, excluding the possibility of performing injury experiments in larger blood vessels. The fact that direct measurements could not be performed constitutes a limitation to our study, however in order to demonstrate a cause -effect relationship between RYRl mutations and vessel response, we used the Pulsed-Wave Doppler and measured velocity of blood flow $(27,28)$, at a point $1 \mathrm{~cm}$ upstream from the incision of the tail artery, at a constant blood pressure (Supplementary Figure 2). Velocity of blood is inversely related to vessel diameter (29) and therefore changes in velocity reflect changes in the contraction and relaxation status of smooth muscle cells. Under baseline conditions, there were no differences in blood flow velocity through the caudal artery between WT and RYR $1_{\mathrm{Y} 522 \mathrm{~S}}$ mice (Figure 1C). However, in response to injury and more specifically at 8-10 minutes post incision, the velocity of blood flow in the tail artery of WT mice was significantly faster than in that of RYR $1_{Y 522 S}$ mice. This result indirectly indicates that vasoconstriction occurs to a larger extent in the tail arteries of WT than in RYR1 Y522S mice.

qPCR experiments confirmed the expression of $R Y R 1$ in primary arterial vascular smooth muscle cells, which was normalized to DES, which encodes desmin, a skeletal and smooth muscle cell-specific protein (30). Cells in mouse aorta and tail artery express the $R Y R I$ transcript, though as expected, to a much lower extent than skeletal muscle (Figure 2A) and the presence of the RYR1 $1_{\text {Y522S }}$ mutation in the heterozygous state does not affect the expression of $R Y R l$ (Figure 2B) no of RYR2 and RYR3 (Supplementary Figure 3). RT-PCR on mRNA isolated from tail 
arteries confirmed the expression of a mutated transcript in the heterozygous $R Y R 1_{Y 522 S}$ mice (Figure 2C). Confocal immunohistochemical analysis on isolated primary vascular smooth muscle cells confirmed the presence of the specific smooth muscle marker actin (Fig. 2D, central panels). Analysis of the subcellular distribution of RyR1 using an antibody that under our experimental conditions does not cross react with RyR2 (Supplementary figure 4) showed that RyR1s are localized close to the plasma membrane (Figure 2E, red). This distribution is similar to that of the voltage sensing dihydropyridine receptor $\mathrm{Ca}_{\mathrm{v}} 1.2$ which is found on the plasma membrane of vascular smooth muscle cells (figure 2E, green) (31-33). The subcellular distribution of RyR1 in isolated primary vascular smooth muscle cells is similar to that reported in pulmonary artery smooth muscle cells and in vas deferens (33-35); in the latter cells, localized RyR1-mediated calcium release from subplasmalemmal stores causes activation of BK channels resulting in cellular hyperpolarization leading to vasodilation $(35,36)$.

\section{Calcium homeostasis in vascular smooth muscle cells isolated from the RYR1 Y522S mouse is significantly different compared to that of their wild-type littermates}

To investigate how $R Y R 1$ mutations affect $\mathrm{Ca}^{2+}$ homeostasis, we isolated primary vascular smooth muscle cells from mouse-tail arteries. We used this cellular model since bleeding times have been assessed on this tissue and these cells are responsible for the control of the vasomotor activity in the tail (37). The resting $\mathrm{Ca}^{2+}$ concentration was similar in primary vascular smooth muscle cells isolated from wild-type and RYR1 $1_{Y 522 S}$ mice (Fig.3 A and B), though the latter cells showed significantly smaller total rapidly releasable $\mathrm{Ca}^{2+}$ stores compared to those isolated from wild-type littermates (Fig.3C). In smooth muscle cells, local calcium release events termed " $\mathrm{Ca}^{2+}$ sparks" have been ascribed to the opening of single or clusters of RyR channels. Although they have little or no direct effect on contraction, they indirectly lead to vasodilation through 
activation of BK channels $(13,18)$. We studied spark activity in isolated primary vascular smooth muscle cells isolated from tail arteries loaded with the fast calcium dye Fluo-4 (Fig. 3D). The frequency of sparks (sparks/image) is given in Figure $3 \mathrm{E}$ and representative videos of sparks occurring in cells from wild-type and RYR1 $1_{\text {Y522S }}$ mice are shown in Supplementary Videos 1 and 2, respectively. Detailed analysis of spark amplitude and kinetics revealed small but significant differences between cells isolated from WT and RYR $1_{\mathrm{Y} 522 \mathrm{~S}}$ knock in mice (Supplementary Table 1) .

We next used several drugs including RyR1 blockers and the $\operatorname{Ins}_{3} \mathrm{R}$ antagonist Xestospongin $\mathrm{C}$ to determine the origin of these spontaneous $\mathrm{Ca}^{2+}$ release event. Sparks were extinguished in wild-type and $\mathrm{RYR} 1_{\mathrm{Y} 522 \mathrm{~S}}$ primary vascular smooth muscle cells by preincubation with Ryanodine (Figure 3E and Supplementary Video 3). Additionally, pre-incubation with dantrolene significantly decreased spark frequency in both wild-type and RYR $1_{Y 522 S}$ cells (Figure 3 E and Supplementary Video 4). This effect was not observed when cells were incubated with the $\mathrm{InsP}_{3}$ antagonist Xestospongin $\mathrm{C}$ (Supplementary Video 5). These results indicated that RyR1 was present in primary vascular smooth muscle cells, that RYR 1 mutations leading to MHS were not only present in skeletal muscle but also in arterial smooth muscle cells, and that the RYR1 $1_{\text {Y522S }}$ mutation increased the frequency of spark events. In skeletal muscle, $R Y R 1$ mutations associated with MHS are gain-of-function mutations leading to an increased sensitivity to activating stimuli, resulting in prolonged and sustained muscle contractions (38-41). Our results suggested that a similar mechanism did not operate in smooth muscle cells since $R Y R 1$ mutations caused prolonged rather than shorter bleeding times, which would be expected if mutated RyR1 caused a gain of function in primary vascular smooth muscle cells. In skeletal muscle, excitationcontraction coupling depends on the mechanical interaction between the voltage sensing dihydropyridine receptor and the RyR1 (42), whereas in smooth muscle cells the functional unit 
is made up of dihydropyridine receptors, ryanodine receptors and $\mathrm{BK}_{\mathrm{Ca}}$ channels $(13,18)$. RyR dependent $\mathrm{Ca}^{2+}$ sparks activate $\mathrm{BK}_{\mathrm{Ca}}$ channels causing plasma membrane hyperpolarization thereby decreasing $\mathrm{Ca}^{2+}$ influx through the dihydropyridine receptor and leading to smooth muscle relaxation $(13,18)$. We found that vascular smooth muscle cells from RYR1 $1_{\mathrm{Y} 522 \mathrm{~S}}$ mice were significantly more hyperpolarized than those from wild-type mice, which had membrane potentials in line with previous reports (18) (Figure 4A). Furthermore, the membrane potential of cells from the RYR1 $1_{\text {Y522S }}$ mice was reverted to control values after treatment with dantrolene (Figure 4A). 


\section{Discussion}

In the present study we demonstrate that gain-of-function $R Y R 1$ mutations associated with $\mathrm{MH}$ and/or exertional rhabdomyolysis cause a mild but distinct bleeding disorder in humans and a corresponding phenotype in a murine model of Malignant Hyperthermia, by affecting vascular smooth muscle cell calcium homeostasis. A model showing how RYRI mutations affect smooth muscle cell contraction is shown in Figure 4B. Characteristic features of the human bleeding phenotype were female preponderance, presentation with marked menorrhagia, postpartum bleeding and a history of miscarriages in the context of normal coagulation tests. Although in our study we evaluated a relatively small sample of $R Y R l$-mutated patients and controls, the clinical data are consistent with the data obtained from the corresponding mouse model carrying the murine equivalent of a human Malignant Hyperthermia-related RYRl mutation (12). The large variation in the bleeding times of $\mathrm{RYR} 1_{\mathrm{Y} 522 \mathrm{~S}}$ mice may reflect different extents of contraction of the skeletal muscles within the mouse tail when placed at $37^{\circ} \mathrm{C}$. Alternatively it may be due to intrinsic structural properties of the RyR complex, which in smooth muscle cells obtained from the tails of RyR $1_{Y 522 S}$ mice has a protomeric composition. A variation in the proportion of protomers encoded by wild-type and mutated alleles within the tetrameric RyR $1 \mathrm{Ca}^{2+}$ channel complex affects the biophysical properties of the RyR1 complex (43) and therefore may account for the variability of the calcium signals responsible for vascular responses. This explanation is in agreement with the data obtained from wild-type mice, which exhibit much more consistent bleeding times, presumably because of the homogeneous protomeric composition within the RyR1 tetrameric protein complex. Our mouse data is also consistent with our findings from humans, in that higher mean bleeding scores correlated with greater variability in $R Y R l$-mutated patients compared to relatives without the familial RYR 1 mutation. Prolonged bleeding times in the RYR $1_{\mathrm{Y} 522 \mathrm{~S}}$ mice and in one patient were reversed by administration of the specific RyR1 
antagonist dantrolene, supporting an association between the observed bleeding phenotype and the RYRl mutant state. These results suggest that dantrolene could be administered as a pharmacological treatment for RYRl-related bleeding disorders and, potentially, other causes of prolonged bleeding due to impaired vascular smooth muscle cell contractility rather than primary platelet or coagulation factor abnormalities. Considering that carriers of Malignant Hyperthermia -associated RYRI mutations are frequent $(1: 2000-1: 3000)(4)$ but often asymptomatic unless exposed to triggering agents, such mutations may account for common mild bleeding abnormalities in humans that are currently without genetic explanation. Of note, we found evidence of abnormal platelet function and borderline reduced vWF levels in 1 and 2 RYR 1 mutated patients within our cohort, respectively. These patients were not considered for the final statistical analysis as we could not exclude a primary platelet or vWF abnormality as an alternative explanation for the observed bleeding phenotype. However, similar findings of mildly abnormal platelet function and vWF levels have been reported in other non-hematological disorders associated with prolonged bleeding such as collagen disorders (44) or Noonan syndrome (45), where the primary defect does not concern platelets or coagulation factors and may therefore well be a secondary feature also in the $R Y R 1$-related bleeding disorder reported in this study.

Our observations are consistent with emerging knowledge concerning the dynamic and complex role of $\mathrm{BK}_{\mathrm{Ca}}$ channels and RyR in tissue-specific vasoregulation: Pressure-induced RyR activation in mesenteric resistance arteries has a strong vasodilatory effect, mediated by $\mathrm{Ca}^{2+}-$ induced activation of $\mathrm{BK}_{\mathrm{Ca}}$ channels and, possibly, $\mathrm{Ca}^{2+}$-induced inactivation of L-type voltagedependent $\mathrm{Ca}^{2+}$ channels (VDCCs) (46). Considering that RyR2 rather than RyR1 is the predominant RyR isoform in murine mesenteric arteries (47), the $R Y R 1$-associated arterial smooth muscle cell phenotype seems unexpected. However, in this context distinct spatial 
distribution may be more important than relative amount of RyR isoforms. As we have demonstrated in murine arterial smooth muscle cells, RyR1s are predominantly found subsarcolemmally, and altered activity of the mutant RyR1s may be more consequential because of their close proximity to $\mathrm{BK}_{\mathrm{Ca}}$ channels. We also cannot exclude the possibility that the release of $\mathrm{Ca}^{2+}$ from mutated RyR1 channels may facilitate the opening of adjacent RyR2 channels through the regenerative $\mathrm{Ca}^{2+}$ induced $\mathrm{Ca}^{2+}$ release mechanism (48).

Our study reports a non-neuromuscular phenotype, that is abnormal bleeding, in RYR1related myopathies and is likely to inform the surveillance and anticipatory management of patients affected by these conditions. Considering that RyR1 is found in many types of tissues, non-neuromuscular manifestations of $R Y R l$ mutations are not unexpected but may have been overlooked, because they are mild and/or involve symptoms that are not necessarily considered part of a neuromuscular disorder. The marked female preponderance in our series with severe menorrhagia and/or post-partum hemorrhage raises the question of more extensive smooth muscle cell involvement in RYRl-related myopathies. Such additional smooth muscle cell involvement may confound the observed bleeding phenotype, in a gender-specific manner in particular on the uterine level, considering that smooth muscle cells also play an important role in uterine vasoregulation and myometrial contraction $(49,50)$. Indeed, patients from two of our families reported prominent bowel and bladder involvement (urinary incontinence, vesicoureteral reflux, "spastic colon"), suggesting more widespread smooth muscle cell involvement also in keeping with a role of both RyRs and $\mathrm{BK}_{\mathrm{Ca}}$ channels in bladder smooth muscle signaling (51). Although beyond the goal of the present study to specifically investigate bleeding abnormalities in patients with $R Y R 1$ mutations, these observations should prompt future investigations into the association between $R Y R 1$ mutations and a more generalized smooth muscle dysfunction both on the clinical and cellular level. 


\section{Materials and Methods}

Patients: Patients were identified through the participating tertiary neuromuscular and malignant hyperthermia $(\mathrm{MH})$ centers. Genetic testing and haematological studies including evaluation of clotting factors and platelet aggregation were performed as part of the routine diagnostic workup. Patients were invited to complete the MCMDM-1VWD (= Molecular and Clinical Markers for the Diagnosis and Management of Type 1 Von Willebrand's Disease) bleeding questionnaire, a validated and widely used diagnostic tool in the evaluation of bleeding disorders (52). MCMDM1-VWD bleeding questionnaires were scored independently by two clinicians blinded to the genetic status (mutated or non-mutated) of the proband. The study received UK Research Ethics Committee approval (15/WS/204, granted by the West of Scotland REC 5). Patients gave informed consent for anonymized publication of their clinical information.

Animal Model: Experiments were carried out on 7-12 week old heterozygous RYR $1_{Y 522 s}$ knockin mice and their wild type littermates. The mouse model was generated by Chelu et al. (12) and was a generous gift of Dr. Susan Hamilton, Baylor College of Medicine, Houston, Texas USA. Experimental procedures were approved by the Veterinary Cantonal Authorities (Permit numbers 1728 and 1729).

Bleeding time assay: Bleeding time was determined according to Liu et al. (25). Intraperitoneal injections with dantrolene $(10 \mathrm{mg} / \mathrm{kg}$ ) or vehicle alone (saline solution) were administered $1 \mathrm{~h}$ prior to bleeding time determination.

Pulsed-wave Doppler: Male mice (15-20 weeks old) were lightly anaesthetized with Ketamine/Xylazine $(95 \mathrm{mg} / \mathrm{Kg}$ Ketamine $+10 \mathrm{mg} / \mathrm{kg}$ Xylazine) and placed on a heated blanket at $26{ }^{\circ} \mathrm{C}$. Blood flow velocity in the tail artery was measured using a Pulse-Wave Doppler ultrasound system (Vevo 2100, VisualSonics Inc., Toronto, Canada) at high frequency (32 MHz, MS 550D transducer). The probe was positioned where a consistent signal could be detected at 
the proximal end of the tail, approximately $1 \mathrm{~cm}$ from the base of the tail. Velocity of blood flow was measured before and at 6 time points after an incision was made on the tail artery; measurements were made $1 \mathrm{~cm}$ upstream from the incision site. The velocity was measured during 5 consecutive cardiac cycles and the mean blood flow velocity per mouse was plotted at each time point before and after incision. The experimenters were blinded and had no prior knowledge of the genotype of the mice. Data were analyzed and plotted using the GraphPad Prism V 6.0 and Origin Pro 8.6.0 softwares.

Blood pressure measurements: Systolic blood pressure was monitored in conscious mice using a non-invasive tail-cuff photoplethysmography sytstem (BP-2000 Blood Pressure Analysis System, Visitech Systems). Blood pressures were assessed in a quiet environment at the same time of day, for a period of 7 days prior to the actual measurements, in order to allow the mice to adjust to the protocol. Each symbol represents the blood pressure value of individual mice.

Isolation of single smooth muscle cells: Primary vascular smooth muscle cells were isolated essentially as described (53) using an enzymatic cocktail containing 9.6 U/ml papain (Sigma \# P4762), 1200U/ml collagenase (Worthington \# LS004176), 2.58U/ml elastase (Worthington \# LS002292), $0.6 \%$ bovine serum albumin (BSA) and $1 \mathrm{mg} / \mathrm{ml}$ soybean trypsin inhibitor (Worthington \# LS003587).

Calcium imaging and Spark analysis: The resting calcium fluorescence was measured using the calcium indicator fura-2 AM (Invitrogen) (26) and the total amount of $\mathrm{Ca}^{2+}$ present in the rapidly releasable intracellular stores was determined as previously described (54). Calcium sparks were measured in cells loaded with $5 \mu \mathrm{M}$ Fluo-4 using a Nikon A1R laser scanning confocal microscope (Nikon Instruments Inc. Melville, USA) with a 60× oil immersion Plan Apo VC Nikon objective (NA 1.4). Five sec duration linescan images $(x, t)$ were acquired in resonant mode 
at super high temporal resolution (7680 lps) with 512 pixels $(0.05 \mu \mathrm{m} / \mathrm{pixel})$ in the $\mathrm{x}$ - and 39936 pixels $(0.126 \mathrm{~ms} /$ pixel $)$ in the t-direction using a pinhole size of $72.27 \mu \mathrm{m}$. Four to five images were taken at different positions across each cell. Fluo-4 was excited with a laser at $487 \mathrm{~nm}$ and the fluorescence emitted at $525+/-25 \mathrm{~nm}$ was recorded. Images were analysed using the open source image processor software Fiji (55). After binning 4X in the temporal axes, linescan images were run with the automated sparks processor plugin SparkMaster (56).

Immunofluorescence: Cells were fixed with ice-cold methanol: acetone (1:1) for $30 \mathrm{~min}$ and processed as previously described (54). The primary antibodies used were: mouse anti-smooth muscle actin (Sigma \#A5228), mouse anti-RyR1 (Thermo Scientific \#MA3-925), rabbit anti$\mathrm{Ca}_{\mathrm{v}} 1.2$ (Santa Cruz \# sc-25686) and the secondary conjugates were anti-mouse Alexa Fluor 568 and chicken anti-rabbit Alexa Fluor 488 (Lubio science). Nuclei were counterstained with DAPI $(25-30 \mu \mathrm{M})$ for 5 min prior to mounting. Cells were examined by confocal microscopy using a Nikon A1R laser scanning confocal microscope with a 60× oil immersion Plan Apo objective.

Real Time qPCR and RT PCR: Total RNA was extracted and treated with deoxyribonuclease I (Invitrogen) as previously described (26). After reverse transcription using 1000-1500 ng of RNA, cDNA was amplified by quantitative real-time PCR with a 7500 Fast Real-Time PCR system (Applied Biosystems) using SYBR Green technology (fast SYBR green master mix, Applied Biosystems) and the following primers: RYRl F: 5'-TCA CTC ACA ATG GAA AGC AG-3'; R: 5'-AGC AGA ATG ACG ATA ACG AA-3'; DES F: 5'-TGA GAC CAT CGC GGC TAA GA-3' and R: 5'-GTG TCG GTA TTC CAT CAT CTC C-3'. Gene expression was normalized to desmin (DES) content as this marker is specifically expressed in muscle cells (30, 57). RYR1 expression levels in mouse aorta, tail artery and mesenteric artery were compared to RYRI expression levels in Extensor Digitorum Longus (EDL), that latter being the reference tissue set to 1. RYRI expression in aorta was also investigated by semi-quantitative RT PCR as 
previously described (26).

Membrane potential measurements: Membrane potential measurements were performed using the potentiometric fluorescence dye Bis-Oxonol as described (58). Briefly, isolated arterial smooth muscle cells were plated on laminin: gelatin (1:10 ratio) pre-coated coverslips and allowed to attach for $20 \mathrm{~min}$ in a modified Krebs-Ringer solution (in $\mathrm{mM}: \mathrm{NaCl}: 140 ; \mathrm{CaCl}_{2}: 0.5$; KCl: 5; $\mathrm{MgSO}_{4}$ : 1; HEPES: 10; $\mathrm{Na}_{2} \mathrm{HPO}_{4}$ : 1; Glucose: 5.5 and Albumin 1\%). Cells were loaded with the potentiometric fluorescence dye Bis-Oxonol (Molecular Probes, B438) in the presence or absence of $20 \mu \mathrm{M}$ dantrolene at room temperature for $30-40 \mathrm{~min}$. To calibrate the membrane potential cells were incubated with the $\mathrm{Na}^{+}$ionophore gramicidin $(10 \mu \mathrm{M})$ (Sigma, G 5002) and then exposed to different $\mathrm{Na}^{+}$containing solutions (Supplementary Figure 5). The concentration ratios of $\mathrm{Na}^{+}$and Choline were varied in order to maintain $\left[\mathrm{Na}^{+}\right]+[$Choline $]=144 \mathrm{mM}$. Theoretical values for membrane potential were calculated according to the formula: Em $=60$ $\log \left(\left[\mathrm{Na}^{+}\right]_{\mathrm{o}}+\left[\mathrm{K}^{+}\right]_{\mathrm{o}}\right) /\left(\left[\mathrm{Na}^{+}\right]_{\mathrm{i}}+\left[\mathrm{K}^{+}\right]_{\mathrm{i}}\right)$, and considering the internal concentration of $\mathrm{Na}^{+}$and $\mathrm{K}^{+}$as described by Nelson et al. (18). Fluorescence was recorded every 0.5 min with a Nikon A1 plus confocal microscope, using a 60X oil objective. Samples were illuminated with a Sapphire Laser at $488 \mathrm{~nm}$ and the fluorescence emitted at 525/50 nm was recorder. Fluorescence images were processed using the open source software Fiji.

Statistical analysis and graphical software: Statistical analysis on the MCMDM1-VWD bleeding questionnaires was performed by converting raw bleeding scores to binary numbers for use in Fisher exact testing with 2-tailed $p$ value (negative screening test $\leq 3$, positive screening test $\geq 4$ ). Mean scores were compared using Student's $t$ test. For all other experiments statistical analysis was performed using the Student's $t$ test; means were considered statistically significant when the $\mathrm{P}$ value was $<0.05$. Data was processed, analysed and plotted using the software 
OriginPro 8.6.0 (OriginLab Corporation). Images were assembled using Adobe Photoshop CS (version 8.0).

\section{Supplementary Information}

Supplementary Figure 1: RYR1 Y522S female mice also exhibit prolonged bleeding times

Supplementary Figure 2: Heart rate and systolic blood pressure are similar in WT and RYR1 $1_{\text {Y522S }}$ mice.

Supplementary Figure 3: Expression of $R Y R 2$ and $R Y R 3$ are not significantly different in the tail arteries of WT and RYR1 $1_{Y 522 S}$ mice.

Supplementary Figure 4: Specificity of the anti-RyR1 antibodies used for IHC.

Supplementary Figure 5: Membrane potential measurements using the fluorescence potentiometric probe Bis-Oxonol.

Supplementary Table 1: Detailed analysis of full kinetic parameters of sparks in vascular smooth muscle cells from WT and RYR1 $1_{\text {Y522S }}$ mice.

Supplementary Video 1: Sparks in smooth muscle cells from WT mice.

Supplementary Video 2: Sparks in smooth muscle cells from RYR $1_{\mathrm{Y} 522 \mathrm{~S}}$ mice.

Supplementary Video 3: Sparks in smooth muscle cells from WT mice after treatment with 10 $\mu \mathrm{M}$ ryanodine.

Supplementary Video 4: Sparks in smooth muscle cells from RYR $1_{Y 522 S}$ mice after treatment with $20 \mu \mathrm{M}$ dantrolene. 
Supplementary Video 5: Sparks in smooth muscle cells from RYR $1_{Y 522 S}$ mice after treatment with $250 \mathrm{nM}$ Xestospongin C. 


\section{References and Notes}

1. Harrison's Principles of Internal Medicine $19^{\text {th }}$ Edition. Eds D. Kasper, A. Fauci, S. Hauser, D. Longo, J. L. Jameson, J. Loscalzo. 2015. McGraw Hill

2. A. Tosetto, G. Castman, F. Rodeghiero, Bleeders, bleeding rates, and bleeding score. $J$. Thromb. Haemost. 11 (Suppl 1), 142-150 (2013).

3. P.H. Shaw, S. Reynolds, S. Gunawardena, L. Krishnamurti, A.K. Ritchey, The prevalence of bleeding disorders among healthy pediatric patients with abnormal preprocedural coagulation studies. J. Pediatr. Hematol. Oncol. 30, 135-141 (2008).

4. N. Monnier, R. Krivosic-Horber, J.F. Payen, G. Kozak-Ribbens, Y. Nivoche, P. Adnet, H. Reyford, J. Lunardi, Presence of two different genetic traits in malignant hyperthermia families: implication for genetic analysis, diagnosis, and incidence of malignant hyperthermia susceptibility. Anesthesiology 97, 1067-1074 (2002).

5. N. Dlamini, N.C. Voermans, S. Lillis, K. Stewart, E.J. Kamstee, G. Drost, R. Quinlivan, M. Snoeck, F. Norwood, A. Radonovic, V. Straub, M. Roberts, A.F. Vrancken, W.L. Van der Pol, R.I. de Coo, A.Y. Manzur, S. Abbs, A. King, M. Lammens, P.M. Hopkins, S. Mohammed, S. Treves, F. Muntoni. E. Wraige, M.R. Davis, B. van Engelen, H. Jungbluth, Mutations in RYR1 are a common cause of exertional myalgia and rhabdomyolysis. Neuromuscul. Disord. 23,540-548 (2013).

6. S. Treves, H. Jungbluth, F. Muntoni, F. Zorzato, Congenital muscle disorders with cores: the ryanodine receptor calcium channel paradigm. Curr. Opin. Pharmacol. 8,319-326 (2008).

7. I. Colombo, M. Scoto, S.A. Robb, L. Maggi, V. Gowda, T. Cullup, M. Yau, R. Phadke, C. Sewry, H. Jungbluth, F. Muntoni, Congenital myopathies: natural history of a large pediatric cohort. Neurology 84, 28-35 (2015). 
8. M. Denborough, Malignant Hyperthermia. Lancet 352, 1131-1135 (1998).

9. C. R. Stephen, Fulminant hyperthermia during anaesthesia and surgery. JAMA 202, 178-182 (1967).

10. W. G. Cullen, Malignant Hyperpyrexia during general anaesthesia: a report of two cases. Canad. Anaesth. Soc. J. 13, 437-443 (1966).

11. J.C. Daniels, I.M. Polayes, R. Villar, F.W. Hehre, Malignant Hyperthermia with disseminated intravascular coagulation during general anaesthesia: a case report. Anesth. Analg. 48, 877-883 (1969).

12. M. Chelu, S. Goonasekera, W. Durham, W. Tang, J. Lueck, J. Riehl, I.N. Pessah, P. Zhang, M.B. Bhattacharjee, R.T. Dirksen, S.L. Hamilton, Heat- and anesthesia-induced malignant hyperthermia in an RyR1 knock-in mouse. FASEB J. 20, 329-30 (2006).

13. M.J. Berridge, Smooth muscle cell calcium activation mechanisms. J. Physiol. 586, 5047-5061 (2008).

14. Y.M. Zheng, Q.S. Wang, Q.H. Liu, R. Rathore, V. Yadav, Y.X. Wang, Heterogeneous gene expression and functional activity of ryanodine receptors in resistance and conduit pulmonary as well as mesenteric artery smooth muscle cells. J. Vasc. Res. 45, 469-479 (2008).

15. T. Vaithianathan, D. Narayanan, M. T. Asuncion-Chin, L.H. Jeyakumar, J. Liu, S. Fleischer, J.H. Jaggar, A.M. Dopico, Subtype identification and functional characterization of ryanodine receptors in rat cerebral artery myocytes. Am. J. Physiol. Cell. Physiol. 299, C264-C278 (2010).

16. X.Q. Li, Y.M. Zheng, R. Rathore, J. Ma, H. Takeshima, Y.X. Wang, Genetic evidence for functional role of ryanodine receptor 1 in pulmonary smooth muscle cells. Pflugers. Arch. 457, 771-783 (2009). 
17. E.B. Westcott, E.L. Goodwin, S.S Segal, W.E. Jackson, Function and expression of ryanodine receptors and inositol 1,4,5-trisphopshate receptors in smooth muscle ells of murine feed arteries and arterioles. J. Physiol. 590,1849-1869 (2012).

18. M.T. Nelson, H. Cheng, M. Rubart, L.F. Santana, A.D. Bonev, H.J. Knot, W.J. Lederer, Relaxation of arterial smooth muscle by calcium sparks. Science 270, 633-637 (1995).

19. J.H. Jaggar, V.A. Porter, J.W. Lederer, M.T. Nelson, Calcium sparks in smooth muscle. Am. J. Physiol. Cell Phyiol. 278, C235-C256 (2000).

20. T. Krause, M. U. Gerbershagen, M. Fiege, R. Weisshorn, F. Wappler, Dantrolene-a review of its pharmacology, therapeutic use and new developments. Anaesthesia 59, $364-373$ (2004).

21. B.R. Fruen, J.R. Mickelson, C.F. Louis, Dantrolene inhibition of sarcoplasmic reticulum $\mathrm{Ca}^{2+}$ release by direct and specific action at skeletal muscle ryanodine receptors. J. Biol. Chem. 272, 26965-26971 (1997).

22. M. Snoeck, B.G. van Engelen, B. Kusters, M. Lammens, R. Meijer, J.P. Molenaar, J. Raaphorst, C.C. Verschuuren-Bemelmans, C.S. Straathof, L.T. Sie, I.F. de Coo, W.L. van der Pol, M. de Visser, H. Scheffer, S. Treves, H. Jungbluth, N.C. Voermans, E.J. Kamsteeg, RYR1-related myopathies: a wide spectrum of phenotypes throughout life. Eur. J. Neurol. 22,1094-1112 (2015).

23. H. Zhou, S. Lillis, R.E. Loy, F. Ghassemi, M.R. Rose, F. Norwood, Multi-minicore disease and atypical periodic paralysis associated with novel mutations in the skeletal muscle ryanodine receptor (RYR1) gene. Neuromuscul. Disord. 20, 166-173 (2010).

24. M. Snoeck, B.G. van Engelen, B. Kusters, M. Lammens, R. Meijer, J.P. Molenaar, J. Raaphorst, C.C. Verschuuren-Bemelmans, C.S. Straathof, L.T. Sie, I.F. de Coo, W.L. 
van der Pol, M. de Visser, H. Scheffer, S. Treves, H. Jungbluth, N.C. Voermans, E.J. Kamsteeg, RYR1-related myopathies: a wide spectrum of phenotypes throughout life. Eur. J. Neurol. 22, 1094-1112 (2015).

25. Y. Liu, N.L. Jennings, A.M. Dart, X.J. Du, Standardizing a simpler, more sensitive and accurate tail bleeding assay in mice. World J. Exp. Med. 2, 30-36 (2012).

26. M. Vukcevic, F. Zorzato F, S. Keck, D.A. Tsakiris, J. Keiser, R.M. Maizels, S. Treves, Gain of function in the immune system caused by a ryanodine receptor 1 mutation. $J$. Cell. Sci. 126, 3485-3492 (2013).

27. C.J. Hartley, A.K. Reddy, S. Mandala, M.L. Entman, L.H. Michael, G.E. Taffet, Doppler velocity measurements from large and small arteries of mice. Am. J. Physiol. Heart Circ. Physiol. 301, H269-H278 (2011).

28. J.C. Sullivan, B. Wang, E.I. Boesen, G. D’Angelo, J.S. Pollock, D.M. Pollock, Novel use of ultrasound to examine regional blood flow in the mouse kidney. Am. J. Physiol. Renal Physiol. 297, F228-F235 (2009).

29. P. J. Pritchard, J. C. Leylegian, R. Bhaskaran, Fox and McDonald's Introduction to Fluid Mechanics. 8th Ed. New York, NY. John Wiley \& Sons, 2015.

30. D. Paulin, Z. Li, Desmin: a major intermediate filament protein essential for the structural integrity and function of muscle. Exp. Cell Res. 301, 1-7 (2004).

31. M.F. Navedo, G.C. Amberg, R.E. Westenbroeck, M.J. Sinnegger-Brauns, W.A. Catterall, J. Striessnig, L.F. Santana, Cav1.3 channels produce persistent calcium sparklets, but Cav1.2 channels are responsible for sparklets in muse arterial smooth muscle. Am. J. Physiol. Heart Circ. Physiol. 293, H1359-H1370 (2007). 
32. M. Gollasch, H. Haase, C. Ried, C. Lindschau, I. Morano, F.C. Luft, H. L. Haller, Ltype calcium channel expression depends on the differentiated state of vascular smooth muscle cells. FASEB J. 12, 593-601 (1998).

33. X.R. Yang, M.J. Lin, K.P. Yip, L.H. Jeyakumar, S. Fleischer, G.P.H. Leing, J.S.K. Sham, Multiple ryanodine receptor subtypes and heterogeneous ryanodine receptorgated $\mathrm{Ca}^{2+}$ stores in pulmonary arterial smooth muscle cells. Am. J. Physiol. Lung Cell Mol. Physiol. 289, L338-L349 (2005).

34. R.E. Lesh, G.F. Nixon, S. Fleischer, J.A. Airey, A.P. Somplyo, A.V. Somlyo, Localization of ryanodine receptors in smooth muscle. Circ. Res. 82,175-185 (1998).

35. L.M. Lifshitz, J.D. Carmichael, F.A. Lai, V. Sorrentino, K. Bellvé, K.E. Fogarty, R. ZhuGe, Spatial organization of RYRs and BK channels underlying the activation of STOCs by $\mathrm{Ca}^{2+}$ sparks in airway myocytes. J. Gen. Physiol. 138, 195-209 (2011).

36. J.H. Clark, N.P. Kinnear, S. Kalujnaia, G. Cramb, S. Fleischer, L.H. Jeyakumar, F. Wuytack, A.M. Evans, Identification of functionally segregated sarcoplasmic reticulum calcium stores in pulmonary arterial smooth muscle cells. J. Biol. Chem. 285, 13542$13549(2010)$.

37. P.T. Nowiki, S. Flavahan, H. Hassanain, S. Mitra, S. Holland, P.J. GoldschmidtClemont, N.A. Flavahan, Redox signalling of the arteriolar myogenic response. Circ. Res. 9,114-116 (2001).

38. S. Treves, A.A. Anderson, S. Ducreux, A. Divet, C. Bleunven, C. Grasso, S. Paesante, F. Zorzato, Ryanodine receptor 1 mutation, dysregulation of calcium homeostasis and neuromuscular disorders. Neuromuscul. Disord. 15, 577-587 (2005).

39. R. Robinson, D. Carpenter, M.A. Shaw, J. Halsall, P. Hopkins, Mutations in RYR1 in malignant hyperthermia and central core disease. Hum. Mutat. 27, 977-989 (2006). 
40. A.D. Lyfenko, S.A. Goonasekera, R.T. Dirksen, Dynamic alterations in myoplasmic $\mathrm{Ca}^{2+}$ in malignant hyperthermia and central core disease. Biochem. Biophys. Res. Commun. 322, 1256-1266 (2004).

41. T. Girard, D. Cavagna, E. Padovan, G. Spagnoli, A. Urwyler, F. Zorzato, S. Treves, Blymphocytes from malignant hyperthermia-susceptible patients have an increased sensitivity to skeletal muscle ryanodine receptor activators. J. Biol. Chem. 276, 4807748082 (2001).

42. S. Fleischer, M. Inui, Biochemistry and biophysics of excitation-contraction coupling. Annu. Rev. Biophys. Biophys. Chem. 18, 333-364 (1989).

43. L. Xu, Y. Wang, N. Yamaguchi, D.A. Pasek, G. Meissner, Single channel properties of heterotetrameric mutant RyR1 ion channels linked to core myopathies. J. Biol. Chem. 283, 6321-6329 (2008).

44. S.C. Jackson, L. Odiaman, R.T. Card, J.G. van der Bom, M.C. Poon, Suspected collagen disorders in the bleeding disorder clinic: a case-control study. Haemophilia. 19, 246-250 (2013).

45. G. Wiegand, M. Hofbeck, M. Zenker, U. Budde, R. Rauch, Bleeding diathesis in Noonan syndrome: is acquired von Willebrand syndrome the clue? Thromb Res. 130, e251-254 (2012)

46. G. Krishnamoorthy, S.K. Sonkusare, T.J. Heppner, M.T. Nelson, Opposing roles of smooth muscle BK channels and ryanodine receptors in the regulation of nerve-evoked constriction of mesenteric resistance arteries. Am. J Physiol. Heart Circ. Physiol. 306, H981-988 (2014). 
47. E.B. Westcott, E.L. Goodwin, S.S. Segal, W.F. Jackson, Function and expression of ryanodine receptors and inositol 1,4,5-trisphosphate receptors in smooth muscle cells of murine feed arteries and arterioles. J. Physiol. 590,1849-1869 (2012).

48. H. Cheng, W.J. Lederer, Calcium sparks. Physiol. Rev. 88, 1491-1545 (2008).

49. Y. Li, R.A. Lorca, X. Ma, A. Rhodes, S.K. England, BK channels regulate myometrial contraction by modulating nuclear translocation of NFkB. Endocrinology 155, 10551063 (2014).

50. C.R. Rosenfeld, T. Roy, Large conductance $\mathrm{Ca}^{2+}$-activated and voltage-activated $\mathrm{K}+$ channels contribute to the rise and maintenance of estrogen-induced uterine vasodilation and maintenance of blood pressure. Endocrinology; 153, 6012-6020 (2012).

51. N. Fritz, J.L. Morel, L.H. Jeyakumar, S. Fleischer, P.D. Allen, J. Mironneau, N. Macrez, RyR1-specific requirement for depolarization-induced Ca2+ sparks in urinary bladder smooth muscle. J. Cell Sci. 120, 3784-3791(2007).

52. M. Bowman, G. Mundell, J. Grabell, W.M. Hopman, D. Rapson, D. Lillicrap, P. James, Generation and validation of the Condensed MCMDM-1VWD bleeding questionnaire for von Willebrand disease. J. Thromb. Haemost. 6, 2062-2066 (2008).

53. S. Tao, D. Yamazaki, S. Komazaki, C. Zhao, T. Iida, Kakizawa, Y. Imaizumi, H. Takeshima, Facilitated hyperpolarization signalling in vascular smooth muscleoverexpressing TRIC-A channels. J. Biol. Chem. 288, 15581-15589 (2013).

54. M. Sekulic-Jablanovic, A. Palmowski-Wolfe, F. Zorzato, S. Treves, Characterization of excitation-contraction coupling components in human extraocular muscles. Biochem. J. 466, 29-36 (2015). 
55. J. Schindelin, I. Arganda-Carreras, E. Frise, V. Kaynig, M. Longair, T. Pietzsch, S. Preiblisch, C. Rueden, S. Saalfeld, B. Schmid, J.Y. Tinevez, D.J. White, V. Hartenstein, K. Eliceiri, P. Tomancak, A. Cardona, Fiji: an open-source platform for biological-image analysis. Nat. Methods 9, 676-682 (2012).

56. E. Picht, A.V. Zima, A. Blatter, D.M. Bers, SparkMaster: automated calcium spark analysis with ImageJ. Am. J. Physiol. Cell Physiol. 293, C1073-C1081 (2007).

57. H. Zhou, O. Rokach, L. Feng, I. Munteanu, K. Mamchaoui, J.M. Wilmshurst, C. Sewry, A. Y. Manzur, K. Pillay, V. Mouly, M. Duchen, H. Jungbluth, S. Treves, F. Muntoni, RyR1 deficiency in congenital myopathies disrupts excitation-contraction coupling. Hum. Mutat. 34, 986-96 (2013).

58. V. Dell'Asta, R. Gatti, G. Orlandini, P. Rossi, B.M. Rotoli, R. Sala, O. Bussolati, G.C Gazzola, Membrane Potential Changes Visualized in Complete Growth Media through Confocal Laser Scanning Microscopy of bis-Oxonol-Loaded Cells. Exp. Cell Res. 231, 260-268 (1997). 
Acknowledgements: We thank Anne-Sylvie Monnet for technical support and our patients for their participation. We thank Dr. Susan Hamilton, Baylor College of Medicine, Houston, Texas USA for the heterozygous RYR1 $1_{\text {Y } 522 S}$ knock-in mice. Funding: This work was supported by a grant from the Swiss National Science Foundation (SNF N³1003A-146198). The support of the Department of Anesthesia Basel University Hospital is gratefully acknowledged. Author Contributions: R.J.L designed and performed the experiments and analysed the results with guidance from F.Z. and S.T.; M.V. performed the first bleeding experiments in the mice and helped measure membrane potential. M.S.J. performed the real time qPCR experiments. L.X. performed the Pulsed-Wave Doppler experiments under the supervision of M.B. H.Z. investigated RyR1 expression in platelets. S.B., M.S., E.C, H.J., J.A., N.V., F.M., A.R., S.M., E.W. were involved in patients selection, identification of mutations, phenotypic and genetic characterization and characterization of bleeding properties. F.Z. and S.T. designed the experiments on the mouse model, oversaw the project and wrote the paper together with H.J.; H.J. made the initial observation of bleeding abnormalities in the patients and conceived the idea for this project together with F.Z and S.T. Competing interests: The authors declare that they have no competing interests. 


\section{Figure Legends}

\section{Figure 1. RYRI mutations are associated with prolonged bleeding times. A.}

Scatterplot of MCMDM-1VWD bleeding scores for RYRI-mutated patients compared to related controls without the familial RYRI mutation(s) (mean score 2.3 in cases compared to -0.4 in controls, $\mathrm{P}<0.005$, Student's $t$-test). Eight out of thirteen female patients had abnormal bleeding scores compare to $0 / 4$ female controls $(\mathrm{P}<0.03$, Student's $t$-test $)$. The mean bleeding score for female patients was 4.5 (range 2 to 9 ), and -1.3 (range -2 to 0$)$ in controls $(\mathrm{P}<0.0005$, Student's $t$ test). B. RYR1 $1_{\text {Y } 522 S}$ knock in MHS mice showed prolonged bleeding times that were reversed by dantrolene. Each symbol represents the bleeding time (in sec) of a single WT (light grey) and RYR1 Y522S (dark grey) mouse. Mice were either untreated, pre-treated with dantrolene or pretreated with vehicle alone. $* * \mathrm{P}<0.05$ Students $t$-test. C. Blood flow velocity in the caudal artery before and after incision. Each symbol represents the mean of 5 measurements performed on each mouse at the indicated time. Light grey symbols, WT mice; dark grey symbols, RYR1 $1_{\text {Y } 522 \mathrm{~S}}$ mice. $* \mathrm{P}<0.004$ and $* * * \mathrm{P}<0.0001$ Student's $t$ test.

Figure 2. RyR1 is present at the mRNA and protein level in aortae and tail arteries and is localized close to the plasma membrane. A. $R Y R l$ expression in skeletal muscle (SKM), aorta, tail (TA) and mesenteric artery (MA) was normalized to DES content, which is present in skeletal and smooth muscle cells (30). The numbers below the bars indicate number of mice used for the analysis. B. The presence of the Y522S mutation does not affect $R Y R 1$ expression as determined by qPCR. The numbers below the bars indicate number of mice used for the analysis. C. Total RNA was extracted from purified aortas and the expression of RYRl was evaluated by RT-PCR. Digestion of the amplified RYRI cDNA from WT mice yielded the uncut band of about $376 \mathrm{bp}$. Digestion of the cDNA from heterozygous RYR1 $1_{\text {Y } 522 S}$ mice yielded two bands of $276 \mathrm{bp}$ and 100 bp plus the uncut $376 \mathrm{bp}$ band from the WT allele. Image is representative of 2 independent 
experiments with 2 mice analyzed per genotype. D. Phase contrast of an isolated primary vascular smooth muscle cell (left); confocal immunofluorescence on the same cell using a mouse antibody specific for smooth muscle actin followed by anti-mouse Alexa Fluor 569 (middle) or DAPI to localize the nucleus (right). Images are representative of cells from 4 mice per genotype. E. Phase contrast on an isolated primary vascular smooth muscle cell (leftmost image). Confocal immunofluorescence of the same cell stained with mouse monoclonal anti-RyR $1 \mathrm{mAb}$ followed by anti-mouse Alexa Fluor-568 (red), rabbit anti-Ca 1.2 followed by anti-rabbit Alexa Fluor-488 (green), DAPI (blue). Composite image showing co-localization of RyR1 and $\mathrm{Ca}_{\mathrm{v}} 1.2$ (rightmost image). Images are representative of cells from 4 mice per genotype. Scale bar $=10 \mu \mathrm{m}$.

Figure 3. Arterial smooth muscle cells from RYR1 $1_{\text {Y522S }}$ mice exhibit smaller intracellular $\mathrm{Ca}^{2+}$ stores and a higher frequency of spontaneous $\mathrm{Ca}^{2+}$ sparks. A. Representative Fura-2 traces of resting fluorescence ratios $(340 / 380 \mathrm{~nm})$ of primary vascular smooth muscle cells isolated from WT (light grey) and a RYR1 $1_{\mathrm{Y} 522 \mathrm{~S}}$ (dark grey) mice. B Mean resting fluorescence ratios from primary vascular smooth muscle cells isolated from 2 WT ( $\mathrm{n}=20$ cells) and 2 RYR1 $1_{\text {Y522S }}$ knock in ( $\mathrm{n}=20$ cells) mice. The values were not significantly different. C. Total amount of $\mathrm{Ca}^{2+}$ in the thapsigargin/ionomycin-sensitive stores was significantly lower in vascular smooth muscle cells from 2 RYR $1_{\text {Y522S }}$ mice ( $n=20$ cells) compared to those from 2 WT ( $n=20$ cells) mice. ${ }^{*} \mathrm{P}<0.05$ Student's $t$ test. D. Top row (left) brightfield image and (right) fluo-4 fluorescent photomicrograph of an isolated smooth muscle cell. Bar, $10 \mu \mathrm{m}$. Bottom, representative pseudocolour and greyscale linescan images of spontaneous localized calcium release events (sparks) in vascular smooth muscle cells. Experiments were performed on cells from WT (top) and RYR1 $1_{\text {Y } 522 S}$ (bottom) mice. The color scale indicates the fluorescence change calculated as the $\mathrm{F} / \mathrm{F}_{0}$ ratio. The traces under the linescan images show the time course of the calcium sparks. Scale bars: vertical $10 \mu \mathrm{m}$, horizontal $100 \mathrm{~ms}$, pseudocolor F/F $\mathrm{F}_{0}$. E. Mean 
$( \pm$ SEM) spark frequency in vascular smooth muscle cells from 6 WT (light grey, $n=28$ cells) and $6 \mathrm{RYR}_{\mathrm{Y} 522 \mathrm{~S}}$ (dark grey, $\mathrm{n}=28$ ) mice. ${ }^{*} \mathrm{P}<0.03 ; * * * \mathrm{P}<0.0001$ Student's $t$ test when comparing cells \pm dantrolene and \pm ryanodine

Figure 4: Smooth muscle cells from $R Y R 1_{Y 522 S}$ mice are more hyperpolarized than those from WT mice, and schematic representation of RyR1 function in arterial smooth muscle cells. A. The resting membrane potential was measured using the potentiometric probe BisOxonol in vascular smooth muscle cells from WT mice (7 controls, $2+$ dantrolene) and RYR1 $1_{\text {Y522S }}$ mice (4 controls and 2 +dantrolene ) (see also Supplementary Figure 5). $\mathrm{n}$ indicates the number of individual cells that were assessed. Cells were either left untreated (control) or pretreated with $20 \mu \mathrm{M}$ dantrolene for 30 minutes.* Mean resting membrane potential was significantly different between WT and RYR1 $1_{\text {Y } 522 S}$ mice (Student's $t$-test $\mathrm{P}<0.05$ ). B. Schematic representation of the mechanism leading to prolonged bleeding time due to $R Y R 1$ mutations. In normal conditions (left panel), early vasospasm occurring immediately after injury reduces bleeding (in coordination with platelets and coagulation factors not shown here). Mutations in RYR1 (right panel) result in hyperpolarization of the smooth muscle cell membrane potential, reducing the ability of vessels to contract and ultimately increasing the bleeding time. PM: Plasma Membrane, SR: Sarcoplasmic Reticulum, RyR1: Ryanodine Receptor Type 1, BK: Calcium activated Potassium Channel. Blue balls: Potassium, peach balls: calcium sparks, WT: Wild Type, RyR1 1 522S : MH knock-in. 
Table 1. Genetic details, neuromuscular features, MCMDM-1VWD bleeding questionnaire scores, and bleeding phenotypes from patients with $R Y R I$-related myopathies and their healthy relatives.

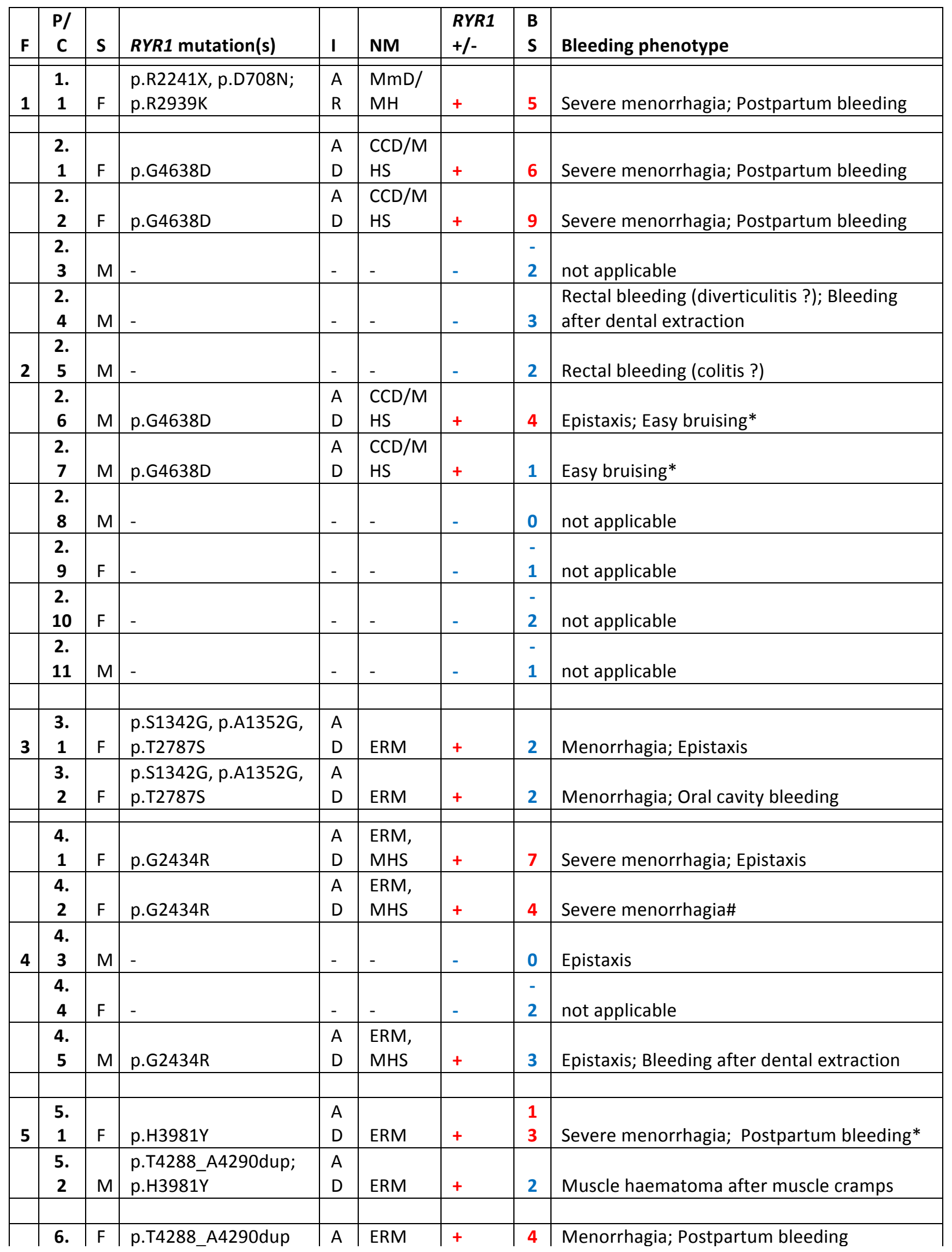




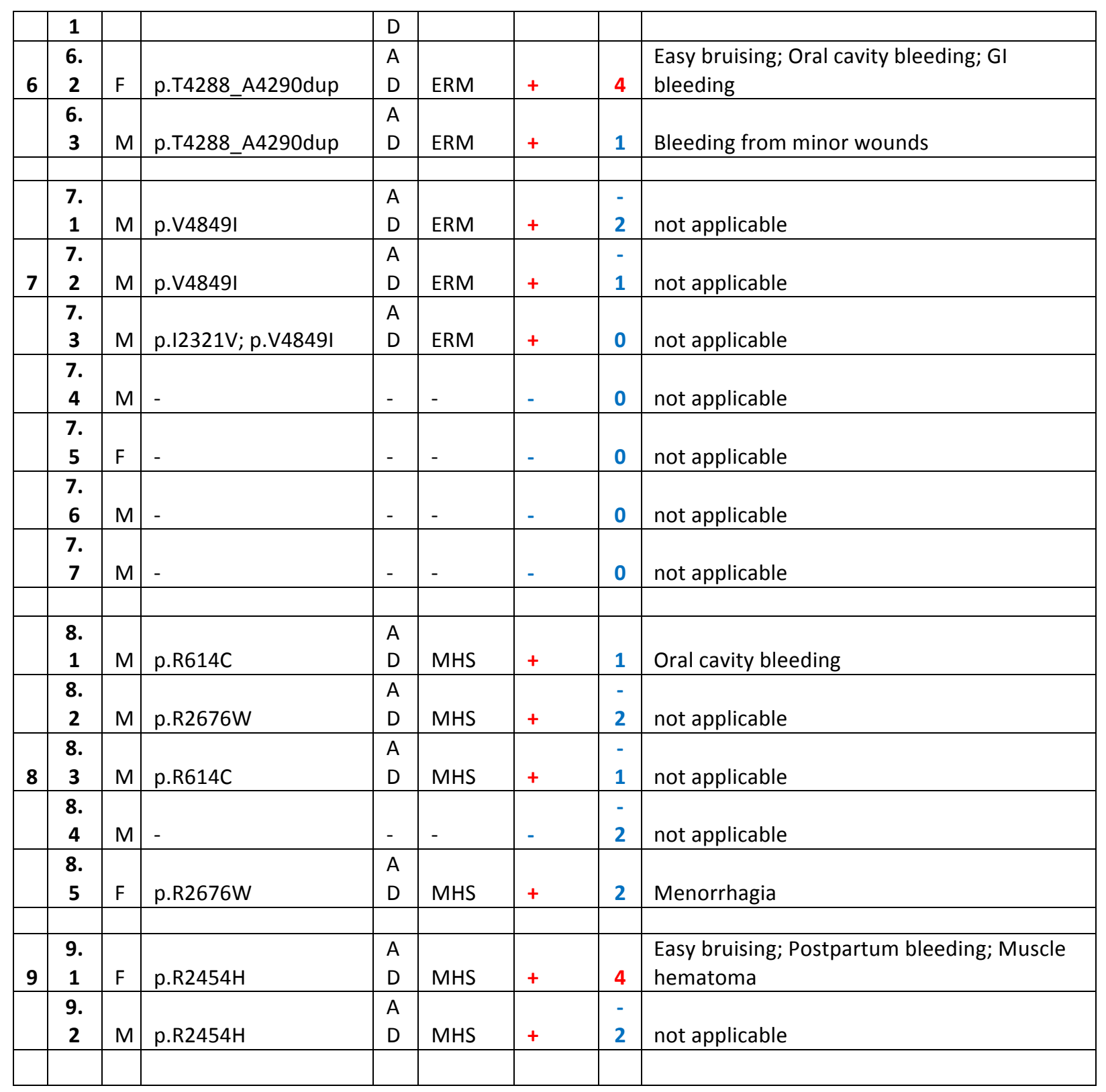

Abnormal MCMDM-1VWD bleeding scores $(\geq 4)$ are highlighted in red. Patient 1.1 was deceased and the MCMDM-1VWD bleeding questionnaire was completed retrospectively based on information in the patient medical notes. *Three patients $(2.6,2.7,5.1)$ were excluded from further statistical analysis because of abnormal von Willebrand factor levels $(2.6,2.7)$ and evidence of abnormal platelet function (5.1), respectively. \#Patient 4.2 reported improvement of bleeding symptoms following commencement of dantrolene treatment, which was prescribed for exertional myalgia. Two dominant heterozygous MHS-related RYR1 mutations were running independently in families 5, 7 and 8. RYR1-mutated individuals in families 2 and 5 reported additional symptoms suggestive of smooth muscle involvement concerning both bladder and bowel (urinary incontinence, vesicoureteral reflux, "spastic colon"). Neuromuscular features from families 1, 2, 4, 6, 7 and 8 have been previously reported. $\mathrm{F}=$ Family; $\mathrm{P} / \mathrm{C}=$ Patient/Control; $\mathrm{I}=$ Inheritance; $\mathrm{NM}=$ Neuromuscular phenotype; $R Y R 1$ +/- = RYRl mutation carrier state; $\mathrm{BS}=$ MCMDM-1VWD bleeding score; 
$\mathrm{CCD}=$ Central Core Disease; MHS $=$ Malignant Hyperthermia Susceptibility; ERM = exertional rhabdomyolysis. 


\section{Figure 1:}

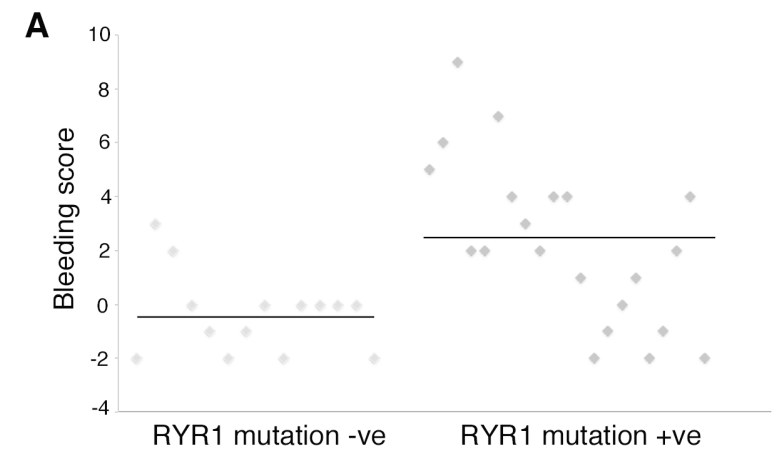

B

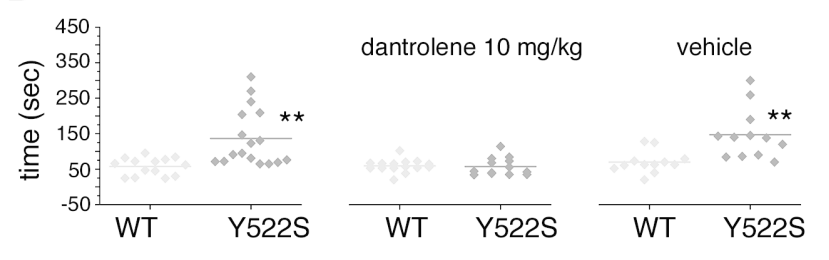

C

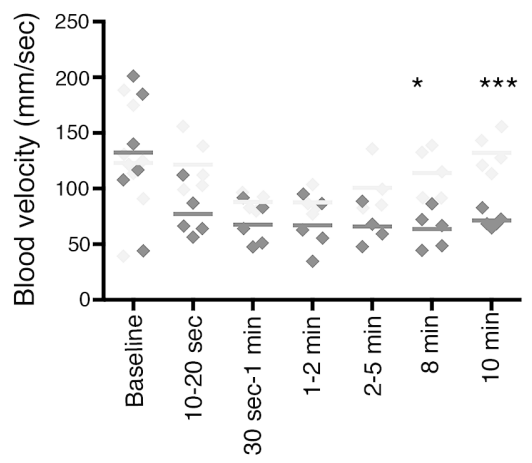

\section{Figure 2:}

A

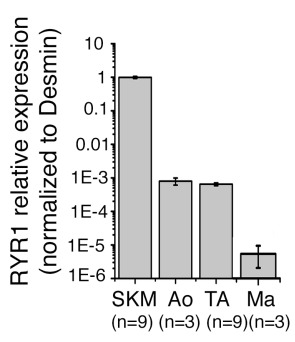

B

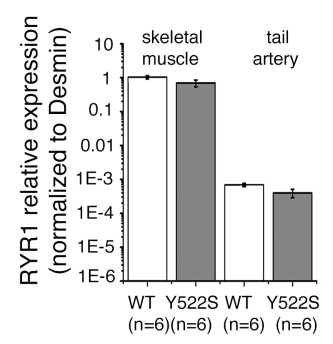

C

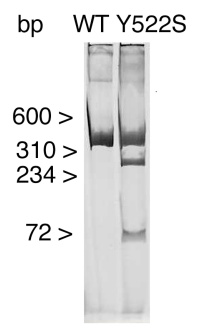

D

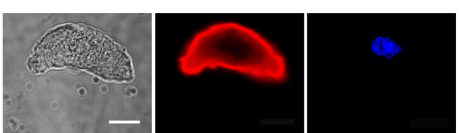

E

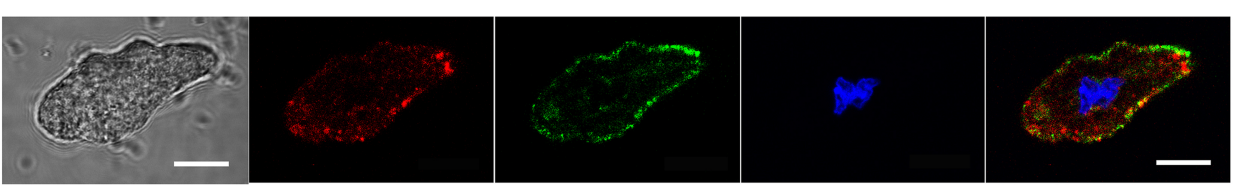




\section{Figure 3:}

A

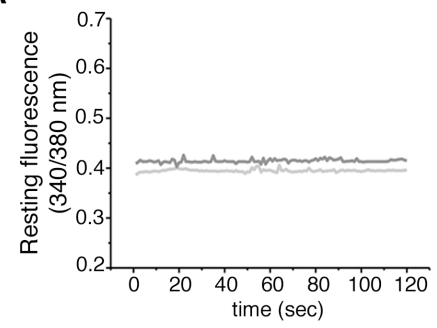

B

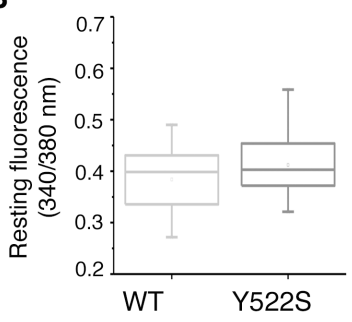

C

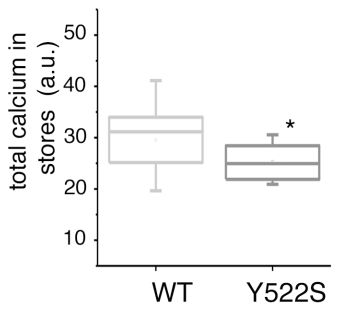

D
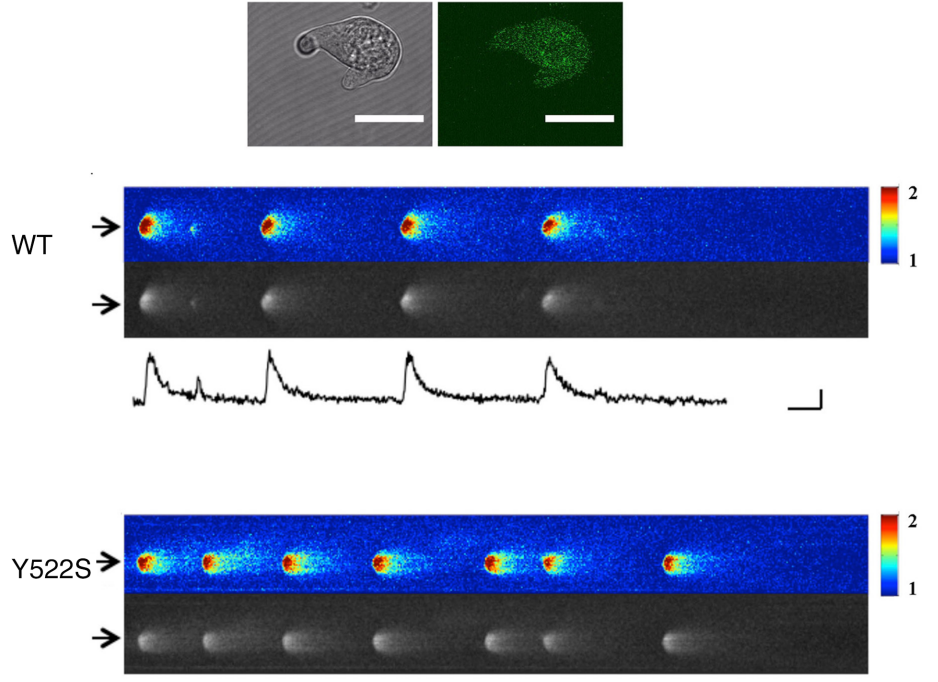

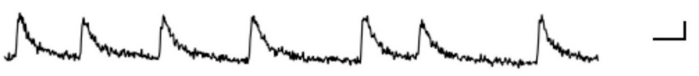

\section{Figure 4:}

A

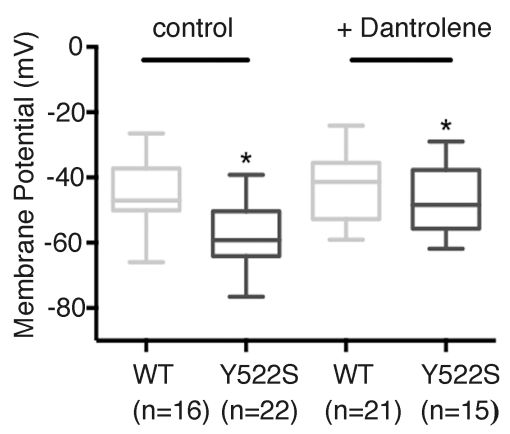
$(n=16) \quad(n=22) \quad(n=21) \quad(n=15)$
E

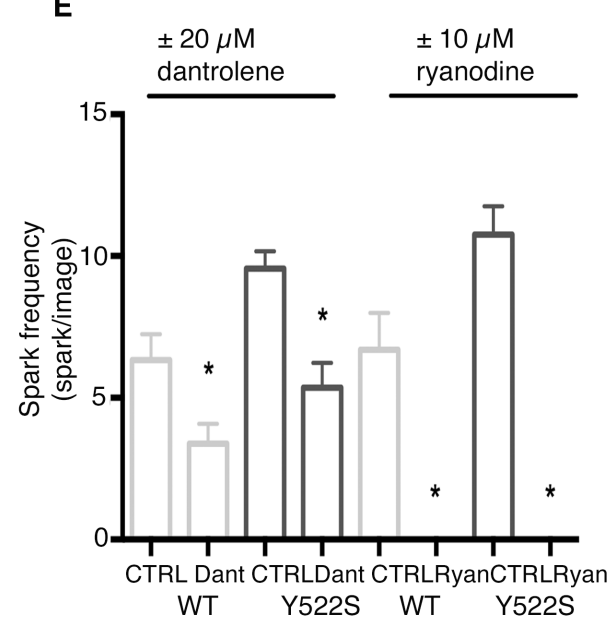

B
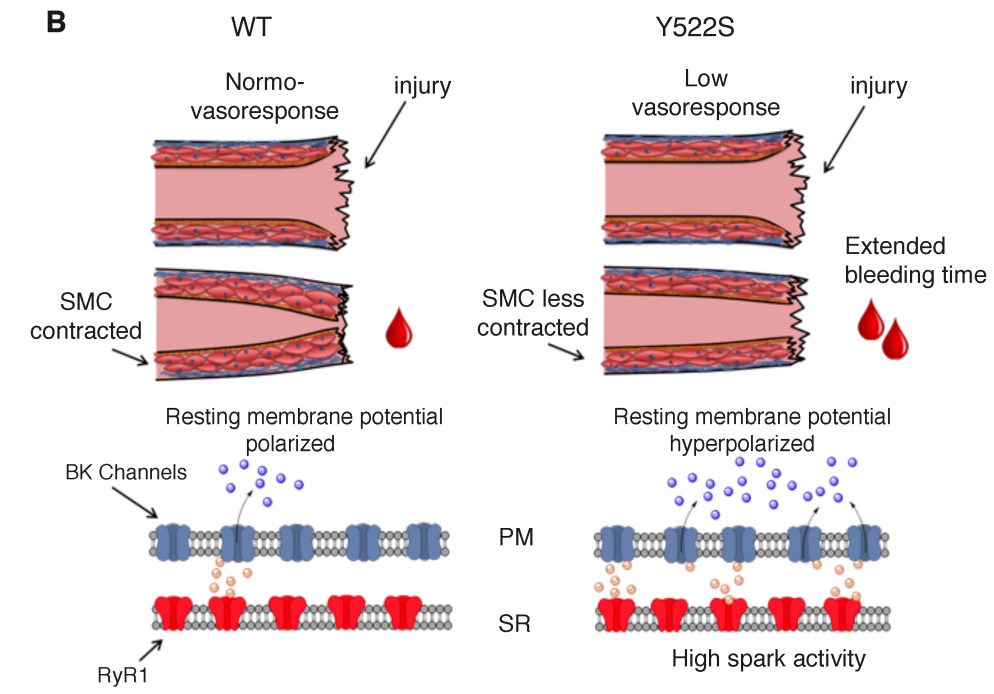